\title{
Software Development Of Parameter Visualization For Cycloidal Gear Profile Used In RV Reducer
}

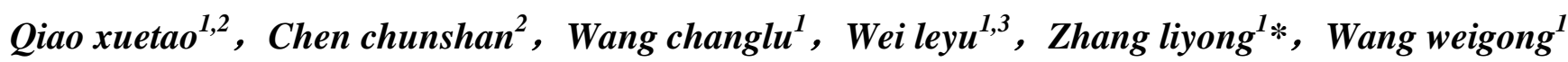 \\ 1.Zhengzhou Research Institute of Mechanical Engineering, zhengzhou, China \\ 2. Zhongyuan University of Technology, zhengzhou, China \\ 3. North China University of Water Resources and Electric Power \\ * corresponding author
}

Keywords: Cycloid Gear Profile ; RV reducer ; Visual Design; Software Development.

\begin{abstract}
Cycloid gear is one of RV Reducer core components used in Robot. Its accuracy of the tooth profile curve plays an important role in meshing transmission of RV Reducer. First of all, the mathematical model of cycloid curve and mathematical model of cycloid gear profile are established in paper. Then, according to the forming principle of cycloid curve, flow chart for parametric design of cycloid curve is done. On this basis, the design platform is developed by GUI program of MATLAB software, in which dynamic forming process of three kinds of cycloid curve can be respectively realized, including the wheel rolling along a straight line, along outside the circumference of a circle and along inside the circumference of a circle. Finally, parametric visual design of the cycloid tooth profile curve could be realized by the software in paper, including epicycloid and hypocycloid. And at the same time, the standard and after modification cycloid gear tooth profile with different parameters could be designed by the software GUI. These works will lay the foundation for the cycloid gear's designing and profile modification and NC machining, and so on.
\end{abstract}

\section{Introduction}

The promulgation of Industry 4.0 and the "Made in China (2025)" greatly promoted the development of industrial robot industry. However, as the core component of industrial robot, $\mathrm{RV}$ reducer has been one of the key technologies of restricting the development of robot industry in China. At the same time, cycloid gear is one of the most important parts in RV reducer. The cycloid tooth profile curve of designing, modification, processing and so on would directly affect the all performance of RV reducer. Therefore, many domestic and foreign scholars have made a lot of further research about the cycloid equation and its properties ${ }^{[1-4]}$. Unlike them, from dynamic simulation perspective, the visual parametric design platform of cycloid profile using Matlab software will be developed in paper, in order to further study the dynamic performance of the RV reducer.

\section{Geometric design}

\subsection{Mathematical model of cycloid curve}

Based on the cycloid formation principle, the cycloid curve is a point moving trajectory generated by a point on the circumference of a circle that rolls along a curve (which is called baseline). The baseline can be both straight line and curve. When the baseline is a straight line, the trajectory is a flat cycloid or an amplitude cycloid. When the baseline is a circle, the trajectory is an epicycloid or a variable amplitude epicycloid or a hypocycloid or a variable amplitude hypocycloid. Figure 1 is schematic diagram of the epicycloid.

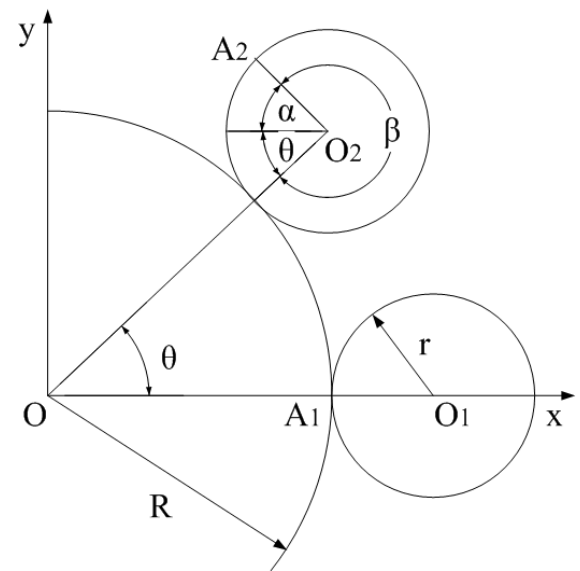

Fig. 1 the formation of epicycloid

According to the above geometric relations, the parameter equation of epicycloid can be derived.

$$
\left\{\begin{array}{l}
x=(R+r) \cos \theta-\cos \left(1+\frac{R}{r}\right) \theta \\
y=(R+r) \sin \theta-\sin \left(1+\frac{R}{r}\right) \theta
\end{array}\right.
$$

Simultaneously, the parameter equation of hypocycloid is: 


$$
\left\{\begin{array}{l}
x=(R-r) \cos \theta+\cos \left(1-\frac{R}{r}\right) \theta \\
y=(R-r) \sin \theta+\sin \left(1-\frac{R}{r}\right) \theta
\end{array}\right.
$$

Where $\mathrm{r}$ is a moving circle radius; $R$ is a base circle radius; $\theta$ is the corresponding central angle of a base circle.

\subsection{Mathematical model of cycloid gear profile}

According to the engage relation of cycloidal gear with the pin wheel in RV transmission, the reasonable coordinates should be established before building the mathematical model of cycloid gear profile. Figure 2 is forming principle of the epicycloid. Circle 1 is basecircle, and Circle 2 is moving circle. Circles 1 and 2 are in internal tangency, and their radius are radii $r_{1}$ and $r_{2}$ separately. As shown in Fig. 3, coordinate systems $\mathrm{S}(\mathrm{X}-\mathrm{O}-\mathrm{Y}), \mathrm{S}_{1}\left(\mathrm{x}_{1}-\mathrm{O}_{1}-\mathrm{y}_{1}\right)$, and $\mathrm{S}_{2}$ $\left(\mathrm{x}_{2}-\mathrm{O}_{2}-\mathrm{y}_{2}\right)$ respectively represents the coordinate system fixed on the frame, pin wheel, and cycloidal gear.

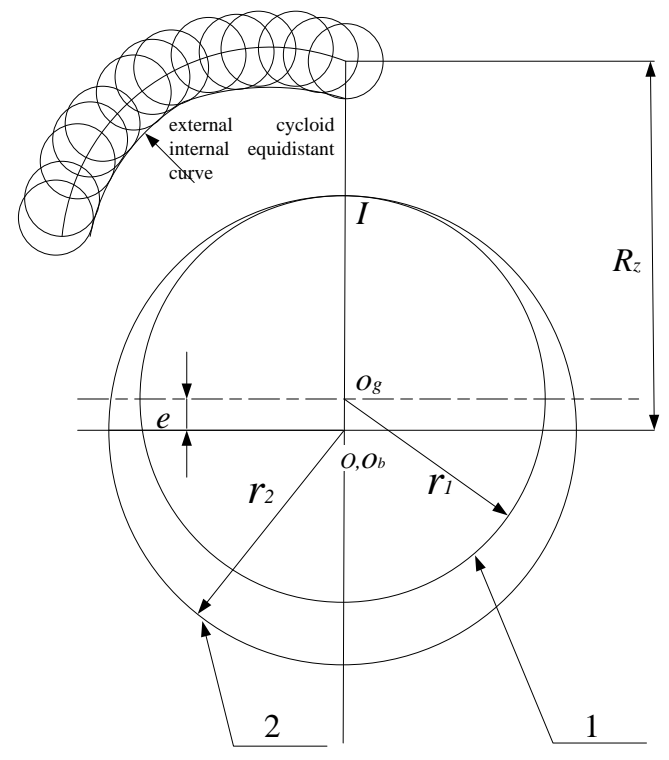

Fig. 2 forming principle of the epicycloid

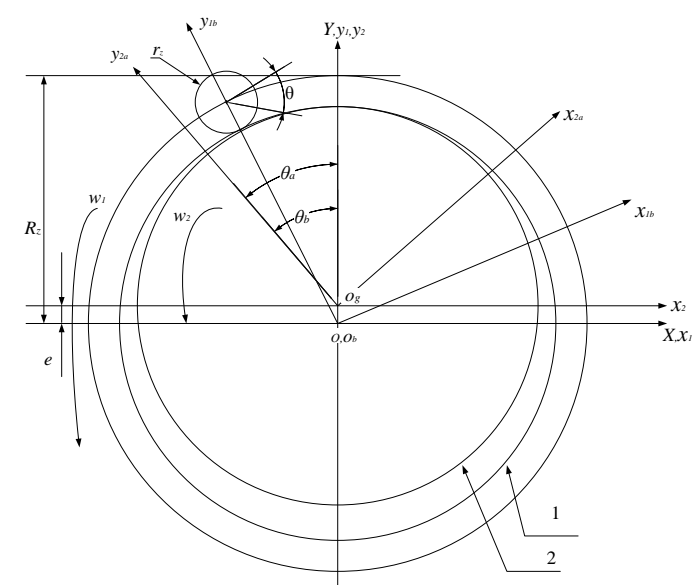

Fig. 3 Coordinate systems for cycloid profile generation
The equation for the cycloidal gear can be determined by coordinate transformation, which can be rewritten as follows [5]:

$$
\left\{\begin{array}{l}
X_{2}=\left\lfloor R_{z}-r_{z} S^{-\frac{1}{2}}\right\rfloor \cos \left[\left(1-i^{H}\right) \varphi\right]-\left[e-K_{1} r_{z} S^{-\frac{1}{2}}\right] \cos \left(i^{H} \varphi\right) \\
Y_{2}=\left[R_{z}-r_{z} S^{-\frac{1}{2}}\right] \sin \left[\left(1-i^{H}\right) \varphi\right]+\left[e-K_{1} r_{z} S^{-\frac{1}{2}}\right] \sin \left(i^{H} \varphi\right)
\end{array}\right.
$$

The equation for the cycloidal gear including modification parameters is:

$$
\left\{\begin{aligned}
X_{2}= & \left\lfloor\left(R_{z}-\Delta r_{p}\right)-\left(r_{z}+\Delta r_{r p}\right) S^{-\frac{1}{2}}\right\rfloor \cos \left[\left(1-i^{H}\right) \varphi-\delta\right] \\
& -\frac{A}{R_{z}-\Delta r_{p}}\left[R_{z}-\Delta r_{p}-Z_{b}\left(r_{z}+\Delta r_{r p}\right) S^{-\frac{1}{2}}\right] \cos \left(i^{H} \varphi+\delta\right) \\
Y_{2}= & {\left[\left(R_{z}-\Delta r_{p}\right)-\left(r_{z}+\Delta r_{r p}\right) S^{-\frac{1}{2}}\right] \sin \left[\left(1-i^{H}\right) \varphi-\delta\right] } \\
& +\frac{A}{R_{z}-\Delta r_{p}}\left[R_{z}-\Delta r_{p}-Z_{b}\left(r_{z}+\Delta r_{r p}\right) S^{-\frac{1}{2}}\right] \sin \left(i^{H} \varphi+\delta\right)
\end{aligned}\right.
$$

Where,

$R_{z}$ — radius of distribution circle, $\mathrm{mm}$;

$r_{z}$ — radius of pin wheel, $\mathrm{mm}$;

$i^{H}$ - - relative transmission ratio between pin wheel and cycloid gear, $i^{H}=\frac{z_{b}}{z_{a}}$;

$\varphi$ — phase angle of meshing, $\operatorname{degree}\left({ }^{\circ}\right)$;

$K_{1}$ - - short width coefficient;

$e$ - - eccentricity, $\mathrm{mm}$;

$S=S\left(K_{1}, \varphi\right)=1+K_{1}^{2}-2 K_{1} \cos \varphi ;$

$\Delta r_{p}, \Delta r_{r p}, \delta$ are profile modifying parameters

\section{Software development of cycloid curve /cycloidal gear profile}

\subsection{Design idea of the software of cycloid gear profile}

The program algorithm is presented from the mathematical model of cycloid curve and cycloidal gear profile. To realize dynamic visual design of different parameters cycloid curve and cycloidal gear profile, the following flow diagram is customized, as shown in figure 4 . This provides an approach for parametric design of cycloid curve and cycloidal gear profile. 


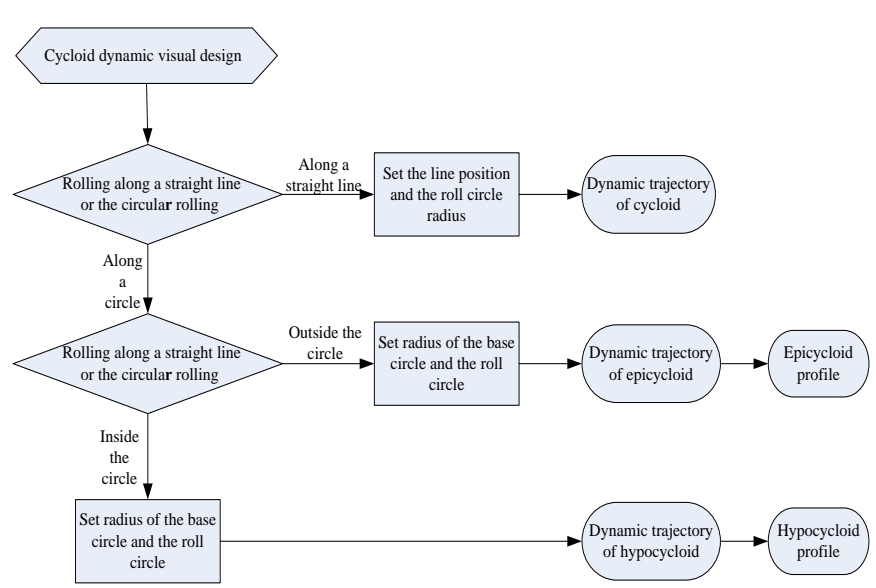

Fig. 4 Flow chart of cycloid dynamic visual design

\subsection{Realization and function of the software}

The purpose of studying the cycloid curve is to obtain more accurate cycloid gear profile. Therefore, on basis of the aforesaid discussion and related literatures ${ }^{[6-12]}$, the software for different parametric visual design of cycloid curve/gear profile is developed in paper. The interface of the software is designed by the graphical user interface (GUI) background program of Matlab software, as shown in fig. 5. Some functions could be realized in the software, such as designing of different types of cycloid curve. We can plot the standard cycloid gear profile with different parameters by the software. We can also draw the cycloid gear profile with different parameters after modification. The software will provide convenience for geometric modeling of the cycloid gear profile. Some interfaces of dynamic visual design for the different parameters cycloidal type curve are designed. For example, the flat cycloid curve can be generated in figure 6 . Dynamic visual design for the different parameters hypocycloid and epicycloid curve could be designed in figure 7-8. Some different parameters cycloid gear could be designed by the software, as shown in fig. 9. Taking cycloid wheel of the RV-20E as an example, cycloidal pin gear pair has been designed by the software, as shown in fig. 10 .

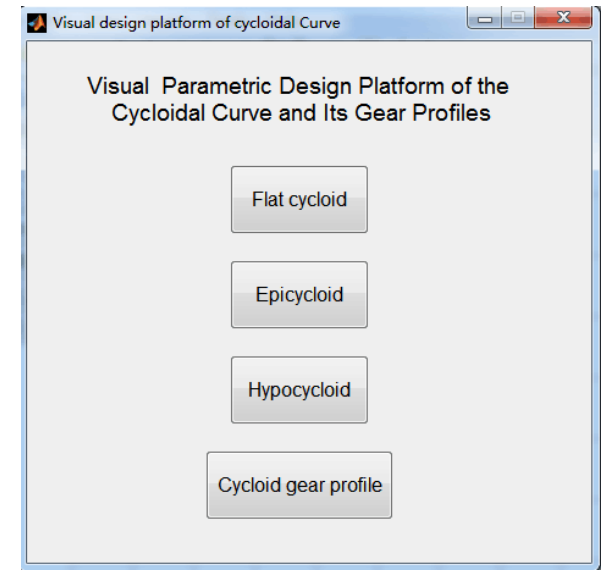

Fig. 5 the interface of dynamic visual design platform for the cycloid curve and its gear profiles

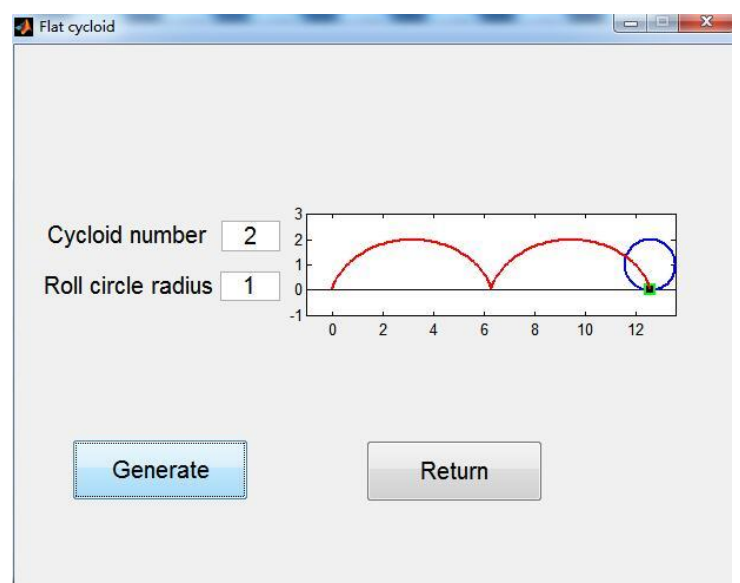

Fig. 6 the interface of dynamic visual design for the different parameters flat cycloid curve

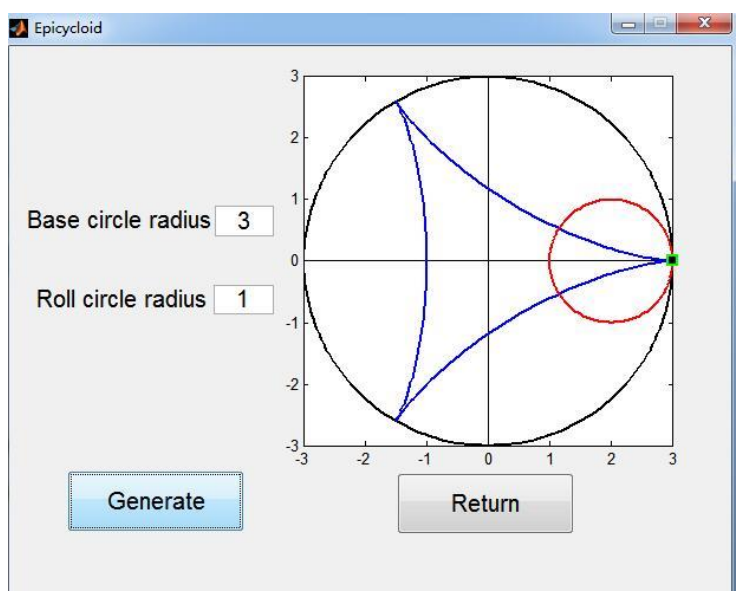

Fig. 7 the interface of dynamic visual design for the different parameters hypocycloid curve

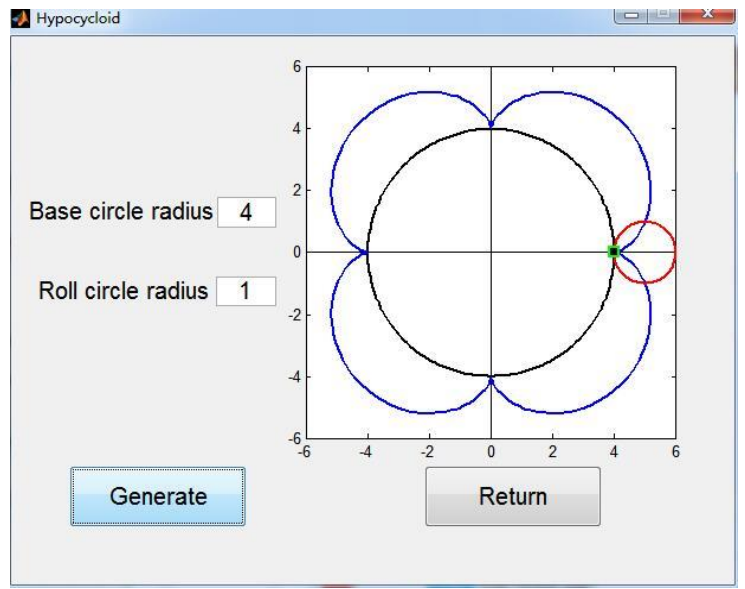

Fig. 8 the interface of dynamic visual design for the different parameters epicycloid curve 


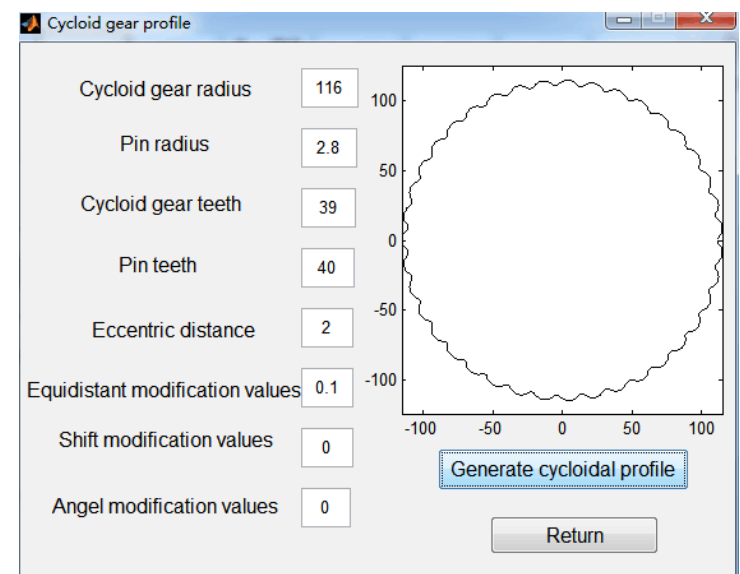

Fig. 9 the interface of dynamic visual design for the different parameters cycloid gear

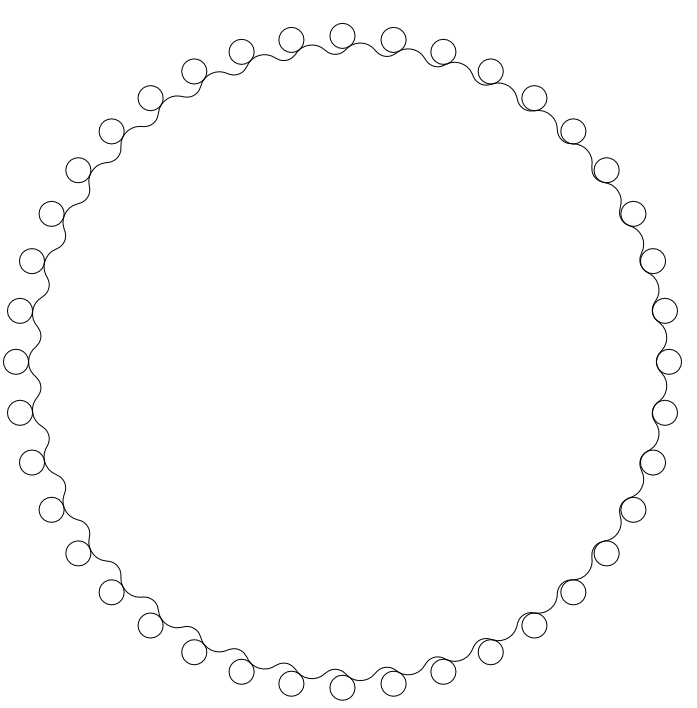

Fig. 10 cycloidal pin gear pair in RV-20E reducer

\section{Conclusion}

Based on the analysis of the mathematical models of cycloid curve and cycloid gear profile, the flow chart of cycloid curve dynamic parametric visual design is presented. Then, the software interface is designed by GUI program of MATLAB software. Three kinds of dynamic forming process of cycloid are respectively realized by means of the special software, including the wheel rolling along a straight line, along outside the circumference of a circle and along inside the circumference of a circle. Next, some functions could be realized in the software, such as designing of different types of cycloid curve. The standard cycloid gear profile and after modification with different parameters could be plot by the software. These works would provide the effective analysis and basis for studying on the meshing theory and tooth profile modification of the cycloidal gear used in $\mathrm{RV}$ reducer.

\section{Acknowledgements}

The project were supported by Henan province Science and Technology Major Project (161100210100) and the Key Laboratory of modern manufacturing equipment and instruments of Henan（No.2017MEI001）.

\section{References}

[1] WANG Baomin. Research onCycloid Characteristics [J]. Mechanical Science and Technology, 2002, 21 (1) : 61 62 (in Chinese)

[2] Yii-Wen Hwang, Chiu-Fan Hsieh. Geometry Design and Analysis for Trochoidal-Type Speed Reducers: with Conjugate Envelopes[J]. Transactions of the CSME, 2006, 30 (2) : $261 \sim 278$

[3] Z. Linlin. Dynamic Model Based on Mathematica 7.0 Design Epicycloid Trajectory [J]. Journal of Xiangyang Vocational and Technical College, 2013, 12 (1) : 31 33 (in Chinese)

[4] W. Wentao, X. Honghai, L. Xueao, F. Yubin. The Theoretical Study About Characteristics of Curtate Cycloid and Its Tooth Profile [J]. Machinery Design \& Manufacture, 2016, 32 (1) : $94 \sim 97$

[5] Yii-Wen Hwang, Chiu-Fan Hsieh. Determination of surface singularities of a cycloidal gear drive with inner meshing $[\mathrm{J}]$. Mathematical and Computer Modelling, 2007, $45(3-4): 340 \sim 354$

[6] CHEN BingKui, FANG TingTing, LI ChaoYang, WANG ShuYan. Gear geometry of cycloid drives[J]. Science in China Series E: Technological Sciences, 2008, 51 (5) : $598 \sim 610$

[7] Z. Luoping, H. Zhenyu, Z. Fengshou, S. Shaojie. Research on Tooth Shape of RV Reducer Cycloidal Gear [J]. Machine Tool \& Hydraulics, 2016, 44 (1) : 32 35 (in Chinese)

[8] Giorgio Figliolini, Hellmuth Stachel, Jorge Angeles. On the synthesis of spatial cycloidal gears[J]. Meccanica, 2013, 48 (5) : $1239 \sim 1249$

[9] Ivan PANTIĆ, Mirko BLAGOJEVIĆ. Kinematic Analysis of Single-Stage Cycloidal Speed Reducer [J]. Mechine Design, 2015, 7 (4) : 113 118

[10] A. I. Siritsyn, V. N. Bashkirov, E. V. Shirokikh, D. A. Sinitsyn. Kinematic Precision of a Planetary Cycloid - Pin Machine - Tool Drive[J]. Russian Engineering Research, 2016, 36 (2) : 89 92

[11] H. Yi, S. Chaosheng. Visual design of cycloid pin gear planetary reducer $[\mathrm{J}]$. Digital Manufacturing Industry, 2006, (6) : 52 53

[12] Pang Su-m in, Chen Xiao-an. The cycloid profile parameterization design and dynamic verification[J]. ModernManufacturingEngineering, 2008, (3) : $50 \sim 53$ (in Chinese) 